\title{
Significados construídos por acadêmicos de licenciatura em Física durante a execução de experimentos de pensamento históricos
}

\author{
Alisson Cristian Giacomelli ${ }^{1}$ \\ http://orcid.org/0000-0002-8490-4132 \\ Cleci T. Werner da Rosa ${ }^{1}$ \\ http://orcid.org/0000-0001-9933-8834 \\ ${ }^{1}$ Universidade de Passo Fundo, Passo Fundo, RS, Brasil
}

\section{RESUMO:}

$\mathrm{O}$ artigo apresenta parte dos resultados de uma pesquisa que visa discutir a potencialidade dos Experimentos de Pensamento (EPs) para a aprendizagem significativa em Física. A questão central da investigação é dada por: como os elementos cognitivos mobilizados pelos estudantes durante a realização de EPs em Física podem ser representativos de indícios de aprendizagem significativa? Para respondê-la, a pesquisa foi estruturada a partir dos resultados da aplicação de dois episódios de ensino envolvendo EPs históricos ("Microscópio de raios gama de Heisenberg" e "Gato de Schrödinger”), juntamente a licenciandos em Física. Para a produção dos dados, foram utilizados os materiais escritos pelos acadêmicos e as videogravações das discussões estabelecidas. Os resultados do estudo, aqui restritos à análise de uma das intervenções realizadas, possibilitaram identificar, frente ao proposto pela Teoria da Aprendizagem Significativa, que os EPs se revelam uma tarefa potencialmente significativa para a construção de significados pelos participantes.
Palavras-chave:

Teoria da

Aprendizagem

Significativa;

Hierarquização dos significados; Ensino de Física.

\section{Significados construidos por estudiantes de profesorado en Física durante la ejecución de experimentos de pensamiento histórico}

\section{RESUMEN:}

Este artículo presenta parte de los resultados de una investigación que tiene como objetivo discutir el potencial de los Experimentos de Pensamiento (EP) para el aprendizaje significativo en Física. La pregunta central de la investigación es: ¿cómo los elementos cognitivos movilizados por los estudiantes durante la realización de los EPs en Física pueden ser representativos de indicios de aprendizajes significativos? Para contestarla, la investigación se estructuró a partir de los resultados de la aplicación de dos episodios de docencia que involucran EPs históricos ("Microscopio de rayos gamma de Heisenberg" y "El gato de Schrödinger"), junto con estudiantes de Física. Para la producción de los datos se utilizaron los materiales escritos por los estudiantes y las grabaciones en video de las discusiones establecidas. Los resultados del estudio, aquí restringidos al análisis de una de las intervenciones realizadas, permitieron identificar, frente a lo propuesto por la Teoría del Aprendizaje Significativo, que los EPs resultan una tarea potencialmente significativa para la construcción de significados de los participantes.
Palabras clave:

Teoría del Aprendizaje Significativo; Jerarquización de significados; Enseñanza de la Física. 


\section{Definitions built by Physics academics during the performance of historic thought experiments}

\section{ABSTRACT:}

The current article presents partial results of a research that aims to discuss the potentiality of Thought Experiments (TEs) for meaningful learning in Physics. The main question of the investigation is given as: how do the cognitive elements mobilized by the students during the TEs in Physics can represent signs of meaningful learning? To answer this question, the article was structured with the results of the application of two teaching episodes involving historic TEs (Heisenberg gamma-ray microscope and "Schrödinger's cat"), together with academics in Physics. For the production of the data, materials written by the academics and video recordings of the established discussions were used. The results of the study, restrict to the analysis of one of the interventions held, made it possible to identify, before the proposal by the Meaningful Learning Theory, that the TEs reveal themselves as a potentially meaningful task for the construction of meanings by the participants.
Keywords:

Meaningful

Learning Theory; Prioritization of meaning; Physics teaching.

\section{INTRODUÇÃO}

Algumas vezes, quando se reflete sobre as criações da imaginação, a primeira ideia que pode vir à mente são mundos fictícios com personagens fantásticos onde tudo é possível, inclusive burlar as leis da Física. A imaginação pode ser entendida como um exercício em que o indivíduo tem total liberdade criativa. Por outro lado, existem atividades imaginativas que demandam o estabelecimento de algumas regras gerais, como é o caso das discutidas no presente estudo. Nele temos como preocupação central a utilização da imaginação que mantém coerência com as leis da Física aceitas pela comunidade científica e que vez ou outra serviram para o desenvolvimento e a divulgação do próprio conhecimento científico. Essas criações da mente que apresentam uma estrutura específica são denominadas de "Experimentos de Pensamento" (EPs) (Brown, 1991).

Sobre a expressão "experimentos de pensamento" e sua variante "experimentos mentais", o destaque fica por conta do físico alemão Ernst Mach (1838-1916), que adotou e popularizou o termo "Gedankenexperiment", expresso na língua inglesa por "Thought experimente". Entretanto, autores como Kiouranis (2009) mencionam que, anteriormente a Mach, Hans Christian Oersted (1777-1851) já havia utilizado a palavra "Gedankenexperiment" com o mesmo significado, mas que foi Mach quem popularizou a expressão e ficou conhecido por empregá-la na ciência. Sem nos atermos a discussões sobre qual a melhor expressão a ser utilizada, temos que os EPs foram e ainda têm sido amplamente utilizados na ciência (Mach, 1972). Destacamos que vários cientistas, cujas contribuições foram reconhecidamente significativas para a produção do conhecimento na ciência, como Galileu Galilei (1564-1642), Isaac Newton (1643-1727) ${ }^{1}$, Michael Faraday (1791-1867), Albert Einstein (1879-1955) e Werner Heisenberg (1901-1976), usaram esses experimentos em seus estudos, como apontado por Helm e Gilbert (1985). Einstein, por exemplo, descreveu o uso de EPs para construir a

\footnotetext{
${ }^{1}$ No calendário juliano, o nascimento de Isaac Newton é datado em 25 de dezembro de 1642; no calendário gregoriano, em 4 de janeiro de 1643.
} 
compreensão de uma série de fenômenos relacionados à Teoria da Relatividade. Tais EPs se baseavam em uma espécie de simulação mental de sistemas constituídos por objetos idealizados, como ondas de luz, dispositivos de medição e eventos relativísticos. Galileu, por sua vez, serviu-se desses experimentos ao descrever a queda de corpos com diferentes massas. A análise das linhas de campo por Faraday também pode ser mencionada como exemplo de um EP que contribuiu de forma significativa para o desenvolvimento da ciência (Helm \& Gilbert, 1985).

Os exemplos mencionados permitem identificar o uso dos EPs no desenvolvimento da ciência ao longo da história, embora, como ressalta Brown (1991), sua definição, assim como de qualquer experimento, seja tema de debate na literatura. Nas palavras do autor: "Eu mencionei que há muito pouca literatura sobre o assunto de experiências de pensamento. Este lamentável estado de coisas está prestes a mudar radicalmente. Dois outros livros logo serão publicados: Nicholas Rescher, Thought Experiments, e Roy Sorensen, Thought Experiments" (Brown, 1991, p. 5). Com isso o autor destaca a eminência de discussões na literatura sobre a temática e busca oferecer contribuições em seu livro para o entendimento desse tipo de experiência. Nesse sentido, Brown (1991) inicialmente esboça uma descrição "grosseira" para tal, afirmando que o experimentador de pensamento imagina algum tipo de situação e, então, deixa-a correr para ver o que acontece. Essa tentativa de definir um EP, ainda que possa parecer vaga, ilustra, de forma simples, o que se faz ao elaborar não somente um EP, mas qualquer tipo de experimento. Ou seja, analogamente a um experimento concreto ${ }^{2}(\mathrm{EC})$, o EP, como descreve Reiner (1998), geralmente atende aspectos como: (a) criação de um mundo hipotético; (b) uma hipótese; (c) uma experiência; (d) resultados baseados em experiências passadas, intuições ou derivações lógicas; e (e) obtenção de uma conclusão baseada em derivações lógicas da evidência e em resultados. Tais aspectos constituem um conjunto de categorias analíticas que foram trazidas por Reiner (1998) a partir da derivação da estrutura sequencial do experimento de pensamento sobre a queda dos corpos apresentado por Galileu (1974). Reiner (1998) utiliza tais categorias como uma ferramenta analítica ao mapear as atividades realizadas por um grupo de estudantes enquanto realizam um EP associado ao estudo da óptica geométrica.

Destacamos que a importância da utilização dos EPs na produção do conhecimento na ciência remete à análise de sua potencialidade como ferramenta didática. Essa possibilidade, além de tomar como referência a presença de tais experimentos na história da ciência, apoia-se na perspectiva, expressa no parágrafo anterior, de que os EPs apresentam uma estrutura semelhante à dos experimentos concretos, cuja validade pedagógica tem sido consagrada, particularmente em se tratando do ensino de Física (Millar, 1987; Arruda \& Laburú, 1998; Hofstein \& Lunetta, 1998).

Os experimentos concretos são amplamente aceitos por pesquisadores, professores e alunos e estão consolidados como estratégia de ensino, divergindo em termos de seus objetivos e de sua estrutura organizacional, mas não de sua aceitação pela comunidade escolar (Borges, 2002). No caso dos EPs, nossa experiência como professores e pesquisadores da área do ensino de Física nos mostra que sua utilização, explicitamente na forma de uma atividade de produção do conhecimento em ciência, tem sido pouco explorada didaticamente, aventando-se a possibilidade de que isso esteja relacionado à sua aceitação como ferramenta didática e, não obstante, à ausência de estudos que mostrem a sua potencialidade na aprendizagem dos conteúdos específicos em Física.

Tal percepção foi corroborada a partir de uma busca por teses e dissertação brasileiras que apresentassem situações didáticas envolvendo o uso dos EPs. Na busca foi localizada a tese

\footnotetext{
${ }^{2}$ Utilizaremos aqui a expressão "Experimentos Concretos" para aqueles experimentos que são realizados no mundo físico, e não apenas na mente.
} 
de Neide Maria Michellan Kiouranis (2009), cujo estudo se pautava pela argumentação promovida pelo uso de um episódio envolvendo o EP da dupla fenda, proposto por Thomas Young. Na procura junto à literatura estrangeira, identificamos os estudos de Reiner (1998), Reiner e Gilbert (2000) e Velentzas e Halkia (2013) como próximos ao problema proposto para este estudo e que talvez pudessem subsidiar a pesquisa, especialmente com intuito de verificar as contribuições dos EPs para aspectos mais específicos da aprendizagem. Os estudos encontrados mostraram situações em que, por exemplo, é anunciado o objetivo de resgatar e consolidar conceitos da Física Clássica e da Mecânica Quântica, como é o caso da tese de Neide Maria Michellan Kiouranis (2009). O estudo de Reiner e Gilbert (2000) anuncia o objetivo de identificar se os estudantes elaboram EPs durante o processo de resolução de problemas e evidenciar os tipos de imagens e conhecimentos corporais usados por eles para imaginar um mundo físico. A análise dos dados evidencia que a imaginação é estruturada e orientada para o objetivo de resolução de problemas. Os autores inferem que as imagens são experienciais e anteriores à tarefa de aprendizagem, sendo consideradas coerentes no processo de resolução dos problemas. Utilizando a imaginação, os alunos podem, por exemplo, girar mentalmente objetos em velocidade constante, "ampliar e diminuir" essa imagem para inspecionar situações hipotéticas, prever caminhos de objetos móveis e imaginar a interação de forças em sistemas mecânicos. Devido a essas possibilidades no uso da imaginação ao realizar EPs, Reiner e Gilbert (2000) destacam a potencialidade desse tipo de experimento para o âmbito educacional.

É possível perceber a potencialidade anunciada pelos autores de os EPs resgatarem e mobilizarem conhecimentos anteriores dos estudantes a fim de resolver determinado problema. Vislumbramos nessas potencialidades a hipótese de se utilizar a Teoria da Aprendizagem Significativa (TAS) como aporte teórico, visto que nesta teoria a mobilização dos conhecimentos preexistentes na estrutura cognitiva dos aprendizes é um elemento central no processo de aprendizagem significativa. Como nenhum dos estudos encontrados fez uma análise a partir dos pressupostos da TAS, nos propusemos a investigar as potencialidades da utilização didática dos EPs para a aprendizagem significativa em Física.

Tais pesquisas, ainda que em número reduzido, apontaram possibilidades didáticas dos EPs no campo da Educação em Ciências, todavia, ainda com a necessidade de investirmos em situações que permitam discutir a potencialidade didática desses EPs para a aprendizagem significativa dos conceitos e fenômenos físicos. Nesse contexto, o problema de investigação se voltou à discussão sobre o uso dos EPs e à possibilidade de ocorrência da aprendizagem significativa, tendo como referencial a TAS a partir da obra de Ausubel, Novak e Hanesian (1983).

Esses aspectos apontados permitiram configurar a questão central do estudo: como os elementos cognitivos mobilizados pelos estudantes durante a realização de EPs em Física podem ser representativos de indícios de aprendizagem significativa? Por elementos cognitivos entendemos aspectos relevantes no processo de aprendizagem significativa e que podem ser expressos, por exemplo, como uma imagem, um símbolo, um conceito ou uma proposição, já significativos para o aprendiz e que interagem com o material/tarefa de aprendizagem. As relações e a organização desses elementos são entendidas como estrutura cognitiva. A partir da questão apresentada, o estudo apresenta como objetivo analisar as contribuições dos EPs históricos e presentes na evolução das ideias na Física, como material potencialmente significativo para a aprendizagem dos conceitos e fenômenos físicos, junto a professores de Física em formação inicial.

Para responder ao questionamento proposto e atingir o objetivo anunciado, foi desenvolvido um estudo envolvendo o processo de aprendizagem significativa mediante dois episódios de ensino em que os EPs históricos estão presentes. Por limitações textuais, nos ocupamos de relatar e discutir neste artigo um deles, que diz respeito a conteúdos relacionados à Mecânica Quântica e foi desenvolvido com um grupo de licenciandos em Física em três 
encontros (um para o teste inicial e dois para discutir situações-problemas associadas ao conceito/fenômeno físico em estudo). Antes de descrever os aspectos metodológicos e adentrar na descrição e análise dos resultados, apresentamos o referencial teórico adotado, como forma de situar o leitor sobre quais aspectos da TAS foram enaltecidos no estudo. Ao final, a título de considerações finais, são destacadas as potencialidades e fragilidades da proposta, assim como apontamentos para futuras pesquisas.

\section{ASPECTOS TEÓRICOS}

Em suas primeiras discussões sobre a TAS, Ausubel, Novak e Hanesian (1983) anunciam dois critérios básicos para que a aprendizagem possa ser significativa: (1) o aprendiz precisa ter uma predisposição para aprender significativamente; e (2) a tarefa (ou material) de aprendizagem precisa ser potencialmente significativa. Em outras palavras, o aprendiz precisa estar disposto a aprender, devendo existir uma intencionalidade para relacionar substantivamente e não arbitrariamente determinado conteúdo. Nesse sentido, mesmo que a tarefa (ou material) de aprendizagem seja potencialmente significativa, se o estudante se esforçar para apenas decorá-la mecanicamente (devido à pressão de uma posterior avaliação, entre outros fatores), a aprendizagem não será significativa, pelo menos em um primeiro momento, o que não necessariamente impede que ela se torne mais adiante. No que diz respeito ao segundo critério, os autores definem que, para ser potencialmente significativa, uma tarefa (ou material) de aprendizagem deve partir dos conhecimentos preexistentes na estrutura cognitiva do aprendiz, ou seja, precisa ser capaz de estabelecer relações com esse conhecimento já existente de forma substantiva e não arbitrária.

A perspectiva teórica ausubeliana está apoiada no entendimento de que há um conhecimento já significativo na estrutura cognitiva do aprendiz, o qual deve ser resgatado para ancorar o novo conhecimento, que, por sua vez, será modificado à medida que se tornar significativo para esse indivíduo. Em outras palavras, Ausubel defende que a aprendizagem significativa representa um processo de interação da nova informação com uma estrutura específica de conhecimento existente no sujeito que aprende. Essa estrutura é denominada de "subsunçor" e representa um conceito, uma ideia, uma proposição já presente na estrutura cognitiva e que poderá servir para ancorar a nova informação, de modo a adquirir significado para o sujeito.

De acordo com Moreira (2016), os subsunçores representam os aspectos relevantes da estrutura cognitiva que são ativados e interagem com o novo conhecimento e que se tornam mais bem elaborados, instáveis, diferenciados e inclusivos. Dessa forma, à medida que o aprendiz relaciona significativamente esses mesmos subsunçores com novos conhecimentos, eles ficam mais abrangentes, bem elaborados e cada vez mais eficientes no sentido de servirem como novos ancoradouros para outros conhecimentos a serem aprendidos no futuro.

A TAS divide a aprendizagem significativa em três tipos fundamentais: aprendizagem de representações, aprendizagem de conceitos e aprendizagem de proposições. O primeiro se aproxima, em certa medida, da aprendizagem por repetição (mecânica), uma vez que ocorre quando o indivíduo estabelece uma equivalência entre o significado de símbolos arbitrários e os seus referentes, por exemplo, objetos, eventos, conceitos, etc. A aprendizagem de representações pode ser significativa quando as proposições de equivalência representacional se relacionam de forma não arbitrária e substantiva, como casos particulares de uma generalização presente na estrutura cognitiva do indivíduo.

A aprendizagem de conceitos se caracteriza pela função simbólica derivada da equivalência entre um símbolo abstrato e os atributos que o definem, regularidades ou critérios 
comuns entre diferentes exemplares de seu referente (Palmero et al., 2008). Esse tipo de aprendizagem significativa ocorre de maneira mais complexa e depende de uma gama razoavelmente ampla de elementos, conforme será discutido mais adiante, quando trataremos da natureza, formação e utilização de conceitos.

A aprendizagem proposicional, por sua vez, consiste em aprender ideias expressas verbalmente, sendo estas constituídas de conceitos, correspondendo, assim, a um significado composto. Não se trata de uma simples soma de vários conceitos, ou seja, para compreender, por exemplo, a proposição "o cachorro é um animal, e, portanto, um ser vivo", é necessário que se compreenda o significado de cachorro, animal e ser vivo. No que diz respeito à compreensão de leis físicas, é possível identificar vários exemplos. Um deles pode ser a Lei de Coulomb para quantificar a força eletrostática, isto é, a força elétrica é diretamente proporcional ao módulo do produto das cargas e inversamente proporcional ao quadrado da distância entre elas. Para que se possa compreender essa proposição, é necessário que se compreenda o significado de força elétrica, carga elétrica e distância.

Ao utilizar como critério de classificação uma organização hierárquica da estrutura cognitiva, Ausubel, Novak e Hanesian (1983) mostram que é possível dividir a aprendizagem significativa em três tipos: subordinada (inclusiva), superordenada e combinatória. A aprendizagem subordinada de conceitos e/ou proposições se dá quando o novo conhecimento se relaciona com proposições e/ou conceitos superordenados específicos presentes na estrutura cognitiva do indivíduo. Nesse tipo de aprendizagem, o novo conhecimento se torna subordinado a ideias mais gerais e inclusivas já existentes na estrutura cognitiva.

A aprendizagem superordenada ocorre quando uma nova proposição ou conceito se relaciona com ideias subordinadas específicas na estrutura cognitiva existente. Nessa categoria, o novo conhecimento se conecta com uma ampla gama de conteúdos genericamente pertinentes presentes na estrutura cognitiva, podendo ser incluído nessa estrutura. Isso ocorre, por exemplo, quando um conceito ou proposição $X$, mais geral e inclusivo do que $\mathrm{x}_{1}, \mathrm{x}_{2} \mathrm{e}_{3}$, é adquirido a partir destes e passa a assimilá-los. Nesse sentido, $X$ assimila $\mathrm{x}_{1}, \mathrm{x}_{2}$ e $\mathrm{x}_{3}$ e passa a ser definido por um conjunto de critérios que abrange $\mathrm{x}_{1}, \mathrm{x}_{2}$ e $\mathrm{x}_{3}$.

A aprendizagem combinatória se refere ao processo em que a nova proposição ou conceito potencialmente significativo não pode se relacionar com uma proposição ou conceito específico já existente na estrutura cognitiva do indivíduo (seja ele subordinado ou superordenado). Nesse caso, ele pode se relacionar com uma ampla gama de conteúdos em geral relevantes na estrutura cognitiva do indivíduo, sem que haja uma hierarquia, permitindo promover a aprendizagem significativa.

A aprendizagem significativa decorre da interação de um novo conhecimento com outro já existente na estrutura cognitiva do indivíduo. À medida que a aprendizagem significativa vai ocorrendo, essa interação leva a que novos conceitos sejam desenvolvidos, elaborados e diferenciados. De acordo com a teoria de Ausubel, o desenvolvimento de conceitos pode ser facilitado ao se introduzir elementos mais gerais e inclusivos em um primeiro momento. Depois ele é progressivamente diferenciado, no que diz respeito a seus detalhes e especificidades. A esse princípio Ausubel dá o nome de "diferenciação progressiva" (Moreira \& Masini, 2001).

Para Ausubel e seus colaboradores, o princípio de diferenciação progressiva deve ser levado em consideração ao se planejar e organizar o conteúdo de uma disciplina. Inicialmente é necessário que se identifiquem quais são as ideias mais gerais e inclusivas da disciplina, e é necessário que estas sejam apresentadas no início, para que posteriormente possam ser progressivamente diferenciadas. Seguindo essa perspectiva, além de promover a diferenciação progressiva, a programação de um conteúdo também deve explorar as relações existentes entre conceitos e proposições, no sentido de identificar diferenças, similaridades e/ou inconsistências, 
reconciliando-as no processo de aprendizagem. A essa recombinação de elementos na estrutura cognitiva Ausubel dá o nome de "reconciliação integrativa" (Moreira \& Masini, 2001).

Cabe destacar que a diferenciação progressiva e a reconciliação integrativa não são processos mutuamente excludentes. Ou seja, toda aprendizagem que gerar reconciliação integrativa resultará também em diferenciação progressiva adicional de conceitos e proposições existentes na estrutura cognitiva do indivíduo. A estrutura cognitiva se trata, portanto, de um processo dinâmico que leva à organização de determinado conteúdo. Essa organização na mente do indivíduo, segundo Ausubel, resulta em uma estrutura hierárquica, onde as ideias mais inclusivas se situam no topo, abrangendo progressivamente conceitos e proposições menos inclusivos e mais diferenciados (Moreira, 2016).

Enfatizamos até este ponto a importância dos conhecimentos prévios no processo de aprendizagem significativa, porém, o que fazer quando não existem tais conhecimentos? A TAS propõe a utilização de organizadores prévios que possam fazer uma ligação entre aquilo que o aluno já sabe e aquilo que ele precisa aprender. Assim, organizadores prévios são materiais introdutórios, apresentados antes do material que precisa especificamente ser aprendido, todavia, em um nível mais alto de abstração, generalidade e inclusividade. Nesse sentido, conforme Moreira (2016), os organizadores prévios não podem ser compreendidos como sumários ou visões gerais do assunto a ser aprendido, pois estes, geralmente, são apresentados no mesmo nível de abstração, generalidade e inclusividade do material que os segue, simplesmente destacando determinados aspectos.

Os conceitos ausebelianos aqui apresentados são utilizados na presente pesquisa tanto em termos da elaboração das situações didáticas como da análise e discussão dos dados. Frente à organização dos episódios de ensino, buscou-se sempre ter o cuidado de identificar inicialmente indícios referentes aos conhecimentos prévios dos estudantes organizando o material a partir dessa identificação. No que tange à análise dos dados, foi possível fazer inferências acerca de indícios de aprendizagem significativa por meio de evidências de diferenciação progressiva e reconciliação integrativa. Além do mais, a hierarquização apresentada pelo autor, dada por aprendizagem subordinada, superordenada e combinatória, foi utilizada como categoria de análise frente aos materiais escritos produzidos pelos estudantes durante a realização dos EPs.

Sobre os aspectos referentes às possíveis definições e classificações dos EPs, destacamos a perspectiva teórica de Brown (1991). De acordo com o autor, uma situação que caracteriza um EP pode ser de dois tipos. O primeiro é a situação "meramente imaginária", ou seja, um experimento que poderia ter sido realizado de forma concreta, porém, por várias razões, é executado somente no pensamento. Segundo ele, outro tipo de EP remete à situação "verdadeiramente imaginada", ou seja, que não poderia sob qualquer circunstância ser realizada em um laboratório físico. Geralmente esse tipo de EP está relacionado a situações muito complexas ou em condições extremas.

Brown (1991) sugere uma taxonomia para os EPs. Conforme o autor, inicialmente os EPs se dividem em dois tipos gerais, chamados de "destrutivo" e "construtivo", respectivamente. Ainda, podemos dividir aqueles que se classificam como construtivos em três tipos adicionais: diretos, conjecturais e mediáticos. Segundo a classificação do autor, há ainda uma classe restrita de EPs particulares que são simultaneamente destrutivos e construtivos. A esses EPs, que o autor diz serem verdadeiramente notáveis, ele dá o nome de "platônicos".

O EPs destrutivos, como o nome sugere, são dirigidos contra uma determinada teoria ou hipótese. Ele destrói ou, pelo menos, apresenta sérios problemas para uma teoria, geralmente, apontando uma lacuna em seu quadro geral. Esse problema pode estar relacionado à própria teoria ou à sua incompatibilidade com outras teorias bem estabelecidas no meio científico. Esses apontamentos sugerem que se destaquem duas classes de EPs destrutivos, aqueles que mostram 
uma teoria inconsistente internamente e aqueles que mostram uma teoria em conflito com ou tras crenças bem estabelecidas (Brown, 1991).

Os EPs do tipo construtivo estão relacionados àqueles experimentos responsáveis pela construção do conhecimento, formulando teorias, testando hipóteses, ou corroborando teorias já existentes. Essa categoria é subdividida pelo autor em três: mediáticos, conjecturais e diretos. No que diz respeito aos EPs construtivos mediáticos, ele afirma que estes são na verdade facilitadores para se chegar a uma conclusão baseada em uma teoria científica específica e bem articulada. Por exemplo, o EP mediático pode ilustrar algum aspecto contraditório da teoria, auxiliando para que esta se torne mais aceitável, ou, ainda, pode simplesmente auxiliar no raciocínio e nas derivações lógicas necessárias para que se possa alcançar o resultado mais facilmente (Brown, 1991).

Um EP do tipo construtivo mediático se embasa em determinada teoria de fundo bem definida, e o experimento atua no sentido de auxiliar na obtenção de uma nova conclusão. Porém, os EPs chamados pelo autor de conjecturais não se embasam em uma teoria bem definida. O ponto fundamental de tais experimentos de pensamento é estabelecer determinado fenômeno, aí então se utiliza uma hipótese para explicá-lo, conjecturando acerca do fenômeno, da hipótese e, consequentemente, da teoria que a sustenta (Brown, 1991).

O último tipo de EP construtivo definido por Brown (1991) é o que ele denomina de "direto". Esse tipo de experimento inicia com um problema, ou seja, de forma parecida com os EPs mediáticos, porém, ao contrário do que ocorre na primeira, nessa classe de EPs, em vez de se partir com uma teoria bem definida, termina-se nela. A propriedade citada se assemelha muito aos EPs conjecturais, porém com a seguinte divergência: um EP direto é formulado a partir de um problema, e a sua resolução desencadeará na teoria; em um EP conjectural, o problema se estabelece a partir da formulação do experimento (Brown, 1991).

Por fim, o autor chama a atenção para um tipo particular de EP, que pode ser simultaneamente construtivo e destrutivo. A esse tipo especial de EP Brown denomina de "platônico". O autor dedica, em seu livro O laboratório da mente, um capítulo inteiro para reivindicar a existência de tais experimentos de pensamento. O nome "platônico" está relacionado à ideia de que esse tipo de EP poderia acessar o conhecimento sobre as leis da natureza a priori. Essa constatação reside no fato de que, como afirma o próprio autor, esse tipo de EP não se baseia em evidências empíricas, nem é resultado de uma derivação de dados antigos.

\section{ASPECTOS METODOLÓGICOS}

O estudo se volta a uma abordagem qualitativa, caracterizando-se como uma pesquisa interpretacionista, em que, segundo Moreira (2002), o interesse central está na interpretação dos significados atribuídos por sujeitos em suas ações associadas a uma realidade socialmente construída. Nesse tipo de pesquisa, as hipóteses são geradas ao longo da pesquisa devido à sua natureza interpretativa. Ao longo da descrição do estudo e análise, por meio de uma narrativa detalhada, o pesquisador busca por credibilidade frente aos seus modelos interpretativos.

A partir dessa compreensão teórico-metodológica, o estudo foi estruturado na forma de episódios de ensino envolvendo a realização de EPs com estudantes de um curso de formação inicial de professores de Física, nos componentes curriculares de Eletromagnetismo I e Física Moderna II. Os objetivos dos episódios de ensino foram os mesmos, variando apenas em relação ao tema apresentado. Por limitações textuais, o presente artigo se ocupa de relatar e analisar um desses episódios, que teve três encontros envolvendo dois EPs associados a segunda 
componente curricular mencionado, quais sejam: "Microscópio de raios gama de Heisenberg" e "Gato de Schrödinger". Os sujeitos do estudo foram quatro acadêmicos de um curso de licenciatura em Física de uma universidade comunitária localizada no interior do Rio Grande do Sul. O estudo teve aprovação do Comitê de Ética em Pesquisa (N. 3.671.380), devidamente cadastrado na Plataforma Brasil.

Em ambos os episódios de ensino selecionados para o presente artigo, foram utilizadas atividades para identificar conhecimentos prévios dos estudantes e situações-problemas como estimuladoras da construção dos EPs. Para a produção dos dados, foram utilizadas as produções escritas pelos estudantes e as videogravações realizadas no ambiente investigado. Os materiais escritos consistem da resolução de situações-problemas propostas pelo pesquisador, que deveriam, conforme orientações prévias, conter o maior número possível de informações, tais como: textos, equações, elementos gráficos, entre outros. Os dados referentes às videogravações tiveram como objetivo trazer mais elementos para as possíveis inferências a serem feitas a partir das produções dos sujeitos de pesquisa.

Em um momento anterior ao desenvolvimento dos EPs, foi aplicado um teste, que denominamos de "teste inicial", envolvendo um conjunto de questões associadas a conceitos e fenômenos considerados como subsunçores para os EPs a serem realizados. O principal objetivo desse teste foi mapear os conhecimentos prévios dos estudantes, cuja identificação é, segundo a TAS, o principal elemento a ser levado em conta ao se planejar uma proposta de ensino que vise à aprendizagem significativa. No caso dos EPs, o foco do teste inicial estava em verificar quais os entendimentos dos estudantes em relação aos conceitos a serem contemplados.

No estudo que é objeto do presente artigo, realizamos a análise dos dados de forma a apresentar inicialmente uma transcrição comentada de alguns dados produzidos e, na sequência, realizar a hierarquização desses dados de acordo com as características sugeridas pela TAS. Desse modo, os dados foram dispostos em tabelas de acordo com a compreensão de aprendizagem subordinada, superordenada e combinatória. Nesse sentido, podemos dizer que, para a análise dos dados, foram utilizadas categorias estruturadas a priori, a partir do padrão estrutural hierárquico dado pela TAS. Essa forma de dispor os dados permitiu uma maior interlocução entre os dados e o referencial teórico adotado para o estudo. Adotamos a hierarquização a partir de elementos associados aos próprios conteúdos específicos, relacionando-os com os dados produzidos pelos estudantes. Ou seja, categorizamos a partir da compreensão geral de que alguns conceitos são mais gerais dentro de certa estrutura de conhecimento, mas também levando em conta as produções dos estudantes.

Antes de adentrarmos à apresentação e análise dos dados, registramos a forma pela qual o episódio de ensino discutido neste texto foi organizado, apresentando, também, os sujeitos e o contexto onde o estudo foi realizado. Definida a problemática e os aspectos teóricometodológicos do estudo, passamos a descrever a estruturação didática das atividades e a forma como os encontros seriam organizados. Para tanto, consideramos as especificidades da TAS e dos EPs, organizando os encontros de maneira a envolver um teste inicial e duas situaçõesproblemas sobre os mesmos conceitos/fenômenos abordados nos EPs, uma para cada encontro.

Nesse sentido, partimos do pressuposto de que o material a ser utilizado deve ser potencialmente significativo, ou seja, precisa estar relacionado com os conhecimentos prévios dos estudantes de forma substantiva e não arbitrária - o que também estava em avaliação nesse estudo. Assim, não foi necessária a utilização de organizadores prévios durante as atividades, porém, o material instrucional, da mesma maneira, foi cuidadosamente organizado para que pudesse estar relacionado com os conhecimentos prévios dos estudantes.

Partindo desses pressupostos, procedemos à seleção do episódio de ensino a ser contemplado no estudo relatado neste texto. O episódio de ensino foi estruturado em dois EPs 
(segundo e terceiro encontros), ambos compreendendo a apresentação de um texto orientador elaborado de forma que pudesse ser relacionável com os conhecimentos prévios dos estudantes (Quadro 7 e Quadro 9). Esses textos foram organizados como situações-problemas que os participantes receberam no início do segundo e terceiro encontros, uma vez que o primeiro esteve reservado para a aplicação do teste inicial. Ao longo das atividades, sempre que necessário, foram feitas interferências por parte do pesquisador e, ao término, foram realizadas discussões coletivas, nas quais era permitido que cada um dos estudantes expusesse seus resultados e métodos, a fim de evidenciar e compartilhar com o grande grupo sua linha de raciocínio.

Destacamos que, durante a realização das atividades envolvendo os EPs, os estudantes puderam interagir entre si de forma a discutir as situações-problemas apresentadas. Contudo, suas análises estavam reservadas à individualidade e, posteriormente, ao compartilhamento dos significados construídos com o grande grupo. Durante a realização das atividades, além de discutirem entre si a situação-problema apresentada, os estudantes poderiam questionar o pesquisador, que era também o professor titular da disciplina na qual as atividades estavam sendo desenvolvidas. Por meio dos diálogos estabelecidos durante a explanação dos significados construídos na proposição do desfecho da situação-problema, somados aos registros dos materiais escritos produzidos pelos estudantes, foi possível fazer inferências sobre eventuais evoluções e refinamentos nos conhecimentos construídos por eles. Essas inferências tomaram por base as possíveis relações entre os dados obtidos e elementos do referencial teórico, tais como a diferenciação progressiva e a reconciliação integrativa. Ou seja, emergiram principalmente da comparação entre os dados obtidos por meio da análise das construções dos estudantes durante a realização dos EPs e aqueles evidenciados no teste inicial.

As atividades não foram dispostas em encontros sequenciais, e os EPs foram introduzidos à medida que se avançava com o conteúdo teórico da disciplina, havendo um intervalo de quase um mês entre a aplicação do primeiro e do segundo EP. Partindo dessas considerações, nos próximos itens, apresentamos os resultados obtidos no estudo.

\section{RESULTADOS}

Num primeiro momento, apresentamos os resultados obtidos com a aplicação do teste inicial (mapeamento de conhecimentos prévios) e, na sequência, focamos nas discussões dos encontros com os respectivos EPs. Para apresentar os registros dos alunos adotamos a identifcação pela letra "A", seguida de uma numeração que vai do 1 ao 4 . A seleção dos alunos para a sequência numérica foi aleatória.

\section{a) Encontro 1 - Identificação dos conhecimentos prévios}

A primeira questão versava sobre os tipos de radiação existentes segundo as leis da Física. Pontua-se que esse conhecimento se mostra necessário na realização do primeiro EP, visto que se trata de um microscópio que utilizará raios gama; nesse sentido, julgamos pertinente que o estudante tivesse clareza do que é a radiação gama e quais os outros tipos de radiação existentes.

Os dados evidenciados a partir da análise das respostas dos estudantes estão dispostos no Quadro 1. 
Quadro 1. Conhecimentos prévios identificados na questão número 1.

Questão número 1: Quais são os tipos de radiação existentes? A1 $\quad$ Radiação eletromagnética, alpha e beta.

A2 No espectro, toda luz é radiação.

A3 $\quad$ Radiação eletromagnética, térmica, alpha, beta e gama.

A4 Energia.

Fonte: Autores.

O experimento do microscópio de raios gama exige em certo momento que os estudantes construam algumas equações. Dado o conhecimento de que todas as equações já haviam sido trabalhadas na disciplina em momentos anteriores à aplicação da atividade, mesmo assim, julgamos que seria pertinente avaliar o conhecimento dos estudantes sobre essas equações.

Como a questão 2 solicitava que o estudante escrevesse somente a equação, organizamos o Quadro 2 de forma que apenas informasse quem conseguiu ou não realizar a tarefa. Como nenhum dos estudantes respondeu incorretamente a questão, embora alguns tenham deixado de respondê-la, optamos por apresentar os dados informando quem respondeu e, alternativamente, quem não respondeu à questão.

Quadro 2. Conhecimentos prévios identificados na questão número 2.

Questão número 2: O momento linear do elétron é dado pela sua massa, velocidade e um fator, chamado fator de Lorentz. Um fóton, por mais que não possua massa, também possui momento linear. Escreva a equação do momento linear do elétron e do fóton.

\begin{tabular}{|l|l|}
\hline A1 & Respondeu corretamente para o fóton e o elétron. \\
\hline A2 & Respondeu corretamente somente para o fóton. \\
\hline A4 & Respondeu corretamente para o fóton e o elétron. \\
\hline
\end{tabular}

Fonte: Autores.

O Efeito Compton havia sido trabalhado com a turma no início do semestre e, nesse sentido, esperávamos que o grupo evidenciasse certo conhecimento sobre o assunto. Esse conhecimento se mostra importante, pois em um dos EPs a serem utilizados no estudo será necessário ter clareza desse efeito. Percebemos, por meio dos dados dispostos nos Quadros $2 \mathrm{e}$ 3 , que em linhas gerais os estudantes possuem uma representação acerca do efeito, porém alguns detalhes específicos não se mostraram tão presentes em suas respostas. Isso pode ter ocorrido pelo que Ausubel, Novak e Hanesian (1983) denominam de "assimilação obliteradora". Ela está relacionada à tendência da estrutura cognitiva de tornar as informações novas progressivamente menos dissociáveis de suas ideias-âncora (subsunçores) até que não mais estejam disponíveis, ou seja, elas deixam de ser reproduzidas como entidades individuais (Moreira, 2016).

Os dados referentes aos significados identificados mediante a análise das respostas dos estudantes se encontram dispostos no Quadro 3.

Quadro 3. Conhecimentos prévios identificados na questão número 3.

\begin{tabular}{|c|l|}
\hline \multicolumn{2}{|c|}{ Questão número 3: Descreva o que você entende por Efeito Compton. } \\
\hline A1 & $\begin{array}{l}\text { De modo simples e utilizando um conceito da Física Clássica, trata-se de uma colisão } \\
\text { elástica entre um fóton e um elétron, onde há uma transferência de energia e quantidade } \\
\text { de movimento do fóton para o elétron. }\end{array}$ \\
\hline A2 & O fóton perde energia ao colidir com um elétron. \\
\hline A3 & Variação no comprimento de onda de um fóton após a colisão com um elétron. \\
\hline A4 & Variação na energia de um fóton após a colisão com um elétron. \\
\hline
\end{tabular}

Fonte: Autores. 
A questão número 4 foi elaborada com o intuito de evidenciar se os estudantes tinham bem estabelecido o significado de superposição. A intenção não era verificar se eles tinham conhecimento acerca do Princípio de Superposição no âmbito da Mecânica Quântica, e sim identificar o significado genérico de superposição que eles apresentariam.

Os dados referentes aos significados evidenciados por meio da análise das respostas dos estudantes se encontram dispostos no Quadro 4.

Quadro 4. Conhecimentos prévios identificados na questão número 4.

Questão número 4: Em Física o que significa superposição? Responda e dê um exemplo de superposição na Física.

\begin{tabular}{|c|l|l|}
\hline $\mathbf{A 1}$ & $\begin{array}{l}\text { Em Física o que significa superposição? } \\
\text { A soma de dois estados que resulta em um } \\
\text { terceiro que é o resultado dessa soma e } \\
\text { caracteriza o sistema. }\end{array}$ & Exemplos de superposição \\
\hline $\mathbf{A 2}$ & Quando duas "coisas" se juntam. & Interferênciância entre duas ondas. \\
\hline $\mathbf{A 3}$ & Dois ou mais estados se misturam em um só. & Superposição de ondas. \\
\hline $\mathbf{A 4}$ & $\begin{array}{l}\text { Duas "coisas" que ocupam a mesma posição } \\
\text { no espaço. }\end{array}$ & Não deu nenhum exemplo. \\
\hline
\end{tabular}

Fonte: Autores.

Como a ideia do EP do "Gato de Schrödinger" é de se chegar ao princípio de superposição, a noção de probabilidade é fundamental, pois a superposição é dada formalmente pela soma de dois possíveis estados que se caracterizam pela probabilidade de o sistema assumir determinada configuração. Nesse sentido, a questão número 5 traz um evento relacionado à Física Clássica, mas que remete à ideia de probabilidade.

Os dados referentes aos significados evidenciados na análise das respostas dos estudantes se encontram dispostos no Quadro 5.

Quadro 5. Conhecimentos prévios identificados na questão número 5.

Questão número 5: Muitas vezes para resolver alguma "disputa" se "tira" cara ou coroa. A ideia é lançar uma moeda verticalmente para cima, apanhando-a quando retorna à sua mão, observando qual das faces da moeda caiu voltada para cima. Discuta o que embasa matematicamente esse "jogo".

A1 A probabilidade de dar cara ou coroa é igual.

A2 Probabilidade de 50\% de dar cara e 50\% coroa.

A3 Desprezando qualquer fator que possa induzir qual face da moeda caia virada para cima, a probabilidade em condições ideais é de $50 \%$ para cada face da moeda.

A4 Probabilidade.

Fonte: Autores.

A questão número 6 trata de uma situação-problema cujo principal objetivo era evidenciar se os participantes do estudo tinham clareza acerca dos conceitos de precisão, exatidão, desvio-padrão e incerteza. Os dados referentes aos significados evidenciados na análise das respostas dos estudantes se encontram dispostos no Quadro 6.

O problema sugerido leva em conta que qualquer dado empírico, mesmo no âmbito da Física Clássica, deve ser obtido considerando fatores como a resolução e sensibilidade dos instrumentos de medida e a precisão das medidas obtidas. Com base nisso, o estudante deve ponderar que, mesmo na Física Clássica, existem limites de incerteza em valores obtidos 
experimentalmente, todavia, o princípio de incerteza de Heisenberg impõe, na Mecânica Quântica, um limite de natureza bastante distinta ao limite clássico.

Tomando como ponto de partida os dados sistematizados a partir da análise do teste inicial, estruturamos os episódios envolvendo os EPs. Destacamos que, por mais que os quadros mostrem algumas lacunas nos conhecimentos prévios dos estudantes, entendemos que estes possuíam os conhecimentos minimamente necessários para a realização dos EPs selecionados para o estudo. Todavia, interpretamos essas lacunas como muito pontuais e descartamos a necessidade de utilizar um organizador prévio, no modo como anunciado pela TAS e descrito na segunda seção deste artigo. O teste aplicado com os estudantes visou identificar conhecimentos prévios aos quais podem ser ancorados os conceitos que integram os dois EPs do presente estudo. Todavia, para aqueles estudantes cujas lacunas de conhecimento se revelaram maiores, o teste pode ter cumprido a função de organizador prévio, tornando-se material introdutório e abrangente capaz de estabelecer uma ponte cognitiva para suprir as lacunas identificadas.

Quadro 6. Conhecimentos prévios identificados na questão número 6.

\begin{tabular}{|c|c|c|}
\hline \multicolumn{3}{|c|}{$\begin{array}{c}\text { Questão número 6: A massa específica da água consiste na razão entre a massa e o volume de } \\
\text { tma certa amostra de água. Um estudante de Física resolve determinar experimentalmente a } \\
\text { massa específica da água. Qual o procedimento que ele pode adotar para obter maior } \\
\text { credibilidade na sua medida? }\end{array}$} \\
\hline & $\begin{array}{l}\text { Como aumentar a credibilidade da } \\
\text { medida? }\end{array}$ & Limites para a precisão. \\
\hline A1 & $\begin{array}{l}\text { Para aumentar a precisão o estudante } \\
\text { poderia repetir várias vezes o } \\
\text { experimento com diferentes volumes } \\
\text { de água. }\end{array}$ & $\begin{array}{l}\text { Na Física Clássica o limite é definido pela } \\
\text { imprecisão dos instrumentos, já na mecânica } \\
\text { quântica, pelo princípio da incerteza. }\end{array}$ \\
\hline A2 & $\begin{array}{l}\text { Manter a água em um ambiente com } \\
\text { pressão normal e temperatura de } 40^{\circ} \mathrm{C} \\
\text { pois essas são as condições em que a } \\
\text { água é mais densa. }\end{array}$ & Não respondeu. \\
\hline A3 & $\begin{array}{l}\text { Levar em consideração o maior número } \\
\text { possível de variáveis e repetir o teste o } \\
\text { maior número possível de vezes. }\end{array}$ & $\begin{array}{l}\text { Tanto na Física Clássica como na Moderna, o } \\
\text { limite de precisão está relacionado aos } \\
\text { instrumentos de medida e ao número de vezes } \\
\text { que se realiza o experimento. }\end{array}$ \\
\hline A4 & $\begin{array}{l}\text { Deve levar em consideração o erro } \\
\text { humano e se a substância é pura, } \\
\text { realizando o experimento o maior } \\
\text { número de vezes possível. }\end{array}$ & $\begin{array}{l}\text { Tanto a Física Clássica como a Moderna } \\
\text { nunca serão completamente precisas. }\end{array}$ \\
\hline
\end{tabular}

Fonte: Autores.

\section{b) Apresentação dos dados produzidos durante a realização dos EPs}

Este item apresenta os dados produzidos durante os episódios de ensino que envolveram a realização dos EPs, iniciando pelo experimento selecionado para cada encontro e trazendo, na sequência, a hierarquização dos dados produzidos pelos estudantes durante a realização do EPs.

\section{i) Encontro 2: EP "Microscópio de raios gama de Heisenberg"}

O primeiro EP selecionado se trata do "Microscópio de raios gama de Heisenberg". Em meados da década de 1920, Werner Heisenberg formulou o Princípio da Incerteza, durante os primeiros passos do que conhecemos hoje como Mecânica Quântica. Para ilustrar esse princípio, ele sugeriu um EP que consiste em levantar a possibilidade de detectar uma partícula pontual, como um elétron. A detecção deveria ser realizada com a maior precisão possível, 
utilizando-se um microscópio de raios gama. No Quadro 7 apresentamos o texto orientador entregue aos estudantes para a realização do EP.

Quadro 7. Texto de apoio para a realização do EP1.

\section{EP1: MICROSCÓPIO DE RAIOS GAMA DE HEISENBERG}

Utilizando as informações fornecidas, desenvolva o experimento de pensamento buscando solucionar os problemas levantados. Todo o andamento do experimento deve ser relatado na folha em anexo, esse relato deve conter o maior número possível de informações, tais como texto, desenhos, diagramas, gráficos, cálculos, etc.

\section{Apresentação da atividade}

Na década de 1920, nos primeiros passos da Mecânica Quântica, Werner Heisenberg formulou um princípio de fundamental importância no desenvolvimento da teoria quântica. Para ilustrar seu princípio, Heisenberg sugere a realização de um célebre e influente experimento de pensamento, conhecido como o microscópio de raios gama. $\mathrm{O}$ experimento consiste em teorizar a possibilidade de detectar (com a maior precisão possível) a posição de uma partícula pontual, como um elétron. Para "ver" (detectar) um elétron é necessário "iluminá-lo" com algum tipo de radiação, no caso, os raios gama. A medição da posição do elétron se constitui pela detecção dos raios gama espalhados por ele.

\section{Formulação do problema}

A figura abaixo é um esquema ilustrativo do experimento de pensamento referente ao microscópio de raios gama. Considere a lente a uma distância d do elétron, e que a sua abertura angular seja $\theta$. Por simplicidade, em nosso experimento vamos considerar inicialmente somente uma dimensão (x). Destacamos que existe um limite quando se observa um objeto pontual por meio de uma lente, ou seja, uma incerteza sobre sua posição exata. Esse limite é definido pela Óptica Geométrica pelo poder de resolução do microscópio; em outras palavras, o poder de resolução define a dificuldade em se poder afirmar com certeza se o elétron está "aqui ou ali". O poder de resolução do microscópio pode ser obtido por meio da equação 1 .

$$
\Delta \mathrm{x}=\frac{\lambda}{\operatorname{sen} \theta}
$$

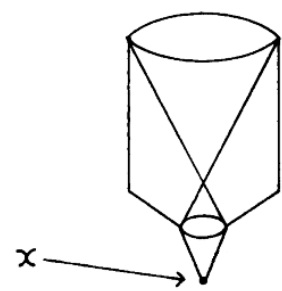

Figura 1. Extraída da obra The Laboratory of the Mind, de James Robert Brown (1991, p. 21).

$1^{\circ}$ Problema: É possível, de alguma forma, ter absoluta certeza sobre a posição do elétron? Como se poderia diminuir a incerteza na posição do elétron utilizando o microscópio de raios gama? O que significa medir a posição do elétron em nosso experimento?

$2^{\circ}$ Problema: Ponderamos agora que nesse experimento, por mais que se diminua a intensidade da fonte de radiação, pelo menos um fóton deve ser espalhado pelo elétron para que ele possa ser detectado. Vamos considerar que o experimento será realizado nessas condições, ou seja, que a fonte emita apenas um fóton por vez, que em seguida é espalhado pelo elétron, regime chamado de monofotônico. Devido ao espalhamento, o elétron recua em uma certa quantidade de acordo com o Efeito Compton. A variação do momento do elétron $\Delta \mathrm{p}_{\mathrm{x}}$ é igual à variação do momento do fóton. Como a direção inicial (anterior ao espalhamento) do fóton não é conhecida, a direção após o espalhamento também não pode ser determinada com certeza. Nesse sentido, o fóton pode ter uma variação de seu momento na coordenada $x$ desde $-p \operatorname{sen} \theta$ até $+p \operatorname{sen} \theta$, ou seja, a variação total é de $\Delta \mathrm{p}_{\mathrm{x}}=2 \mathrm{psen} \theta$.

Baseado no exposto, defina a incerteza na coordenada $\mathrm{x}$ do momento do elétron espalhado $\mathrm{e}$ calcule o produto entre a incerteza da posição $\Delta \mathrm{x}$ (definida no problema anterior) e do momento $\Delta \mathrm{p}_{\mathrm{x}}$. Como se poderia diminuir a incerteza no momento do elétron utilizando o microscópio de raios gama? 
Seria possível reduzir infinitamente e simultaneamente a incerteza do momento e da posição do elétron?

Fonte: Autores.

A proposta foi realizar essa atividade com os estudantes nos moldes de uma sala de aula invertida, envolvendo um momento anterior à aula que abordaria o Princípio de Incerteza de Heisenberg. Ou seja, o intuito foi de que funcionasse como um EP introdutório, no qual os estudantes poderiam construir seus primeiros significados acerca do conteúdo. A formulação mais precisa, assim como as aplicações e consequências mais amplas desse princípio foram trabalhadas com a turma na sequência das aulas do componente curricular. Entendemos que o EP serviu didaticamente para que os estudantes estabelecessem as relações entre as variáveis associadas ao princípio de incerteza. Visto que essas relações são de fundamental importância para o entendimento do princípio, julgou-se pertinente a utilização deste EP como elemento problematizador aplicado de forma introdutória ao conteúdo.

\section{Apresentação dos significados identificados - Encontro 2}

Mediante a análise das produções escritas pelos estudantes durante a realização do EP1, identificamos a construção de significados por parte deles. Essa construção, que será hierarquizada na próxima subseção, toma como referência os registros transcritos a seguir, que correspondem a excertos selecionados a partir dos registros e que tiveram a linguagem corrigida.

Com relação ao EP1 apresentado no Quadro 7, temos os seguintes registros dos participantes:

A1 - Não é possível diminuir indefinidamente a incerteza da posição ou do momento do elétron; visto que o lado esquerdo da igualdade é um produto entre $\Delta x$ e $\Delta p x$, nesse caso, ao diminuir um dos valores, o outro deveria aumentar para manter a igualdade; é impossível conhecer com precisão a posição e o momento do elétron simultaneamente.

A2 - Não é possível ter $100 \%$ de certeza sobre a posição do elétron; diminuindo o comprimento de onda, aumenta-se a precisão na medida da posição; quando você mede a posição do elétron, a área variada pelo raio gama sempre vai ter uma largura, isso faz com que não se tenha total certeza de onde ele está; ao diminuirmos a incerteza na posição, aumenta-se a incerteza no momento.

A3 - Quanto menor for $\lambda$, menor a incerteza na posição do elétron e vice-versa; diminuindo o comprimento de onda do fóton, diminuímos a incerteza na posição do elétron, visto que a área "varrida" pelo fóton seria menor; quanto mais aumentamos a precisão na medida da posição mais isso interfere na precisão do momento; é impossível reduzir simultaneamente as duas incertezas.

A4 - Se eu diminuo o comprimento de onda, a medida da posição fica mais precisa, porém isso interfere na medida do momento. Não é possível determinar a posição e o momento do elétron simultaneamente.

O EP1 também solicitava que os estudantes obtivessem uma relação matemática para o produto entre a incerteza da posição $\Delta \mathrm{x}$ e a incerteza no momento $\Delta \mathrm{px}$. Nesse item todos os estudantes conseguiram chegar na relação matemática pretendida. A4 apenas não fez os últimos ajustes possíveis, ou seja, obteve a relação: $\Delta \mathrm{px}=2 \mathrm{p} \lambda / \Delta \mathrm{x}$. Nesta equação era possível deixar do lado esquerdo apenas o produto $\Delta \mathrm{x} . \Delta \mathrm{px}$ e, do lado direito, substituindo $\mathrm{p}$ por $\mathrm{h} / \lambda$, restaria apenas $2 \mathrm{~h}$. Destacamos que somente a reprodução da equação não pode ser tomada como indício de aprendizagem significativa, porém, conciliando esse dado com outros elementos, é possível 
identificá-lo. Todavia, isso não significa que a relação obtida por A4 esteja incorreta, e sim que apenas faltaram os últimos ajustes para simplificá-la, deixando seu significado mais claro.

\section{Hierarquização dos significados construídos durante o Encontro 2}

Neste item classificamos os significados produzidos pelos estudantes de acordo com o seu grau de subordinação a partir da análise dos materiais escritos elaborados durante a realização do EP1. No que diz respeito à aprendizagem subordinada, consideramos os significados produzidos pelos estudantes que pudessem ser relacionados ao conceito geral de incerteza. Ou seja, existe na Física uma concepção genérica de incerteza que não necessariamente está associada ao Princípio de Incerteza de Heisenberg, significado a ser construído durante a realização do EP1. Nesse sentido, classificamos como subordinados os significados mais específicos que pudessem ser relacionados ao significado mais geral e inclusivo de incerteza. Como superordenados classificamos os significados mais gerais que se relacionavam com conhecimentos específicos da estrutura cognitiva dos estudantes, estes associados à relação de incerteza existente entre duas grandezas físicas - por exemplo, a ideia de que, se diminuirmos a incerteza no momento, aumentamos a incerteza na posição. Essa conclusão muitas vezes esteve associada à relações com conhecimentos específicos já existentes na estrutura cognitiva dos estudantes, como, por exemplo: aos processos de medição em si, ao Efeito Compton, entre outros. Para a aprendizagem combinatória classificamos os significados que se relacionaram com a estrutura cognitiva de forma mais geral, no caso, os relacionados aos conceitos de exatidão, precisão e incerteza.

Quadro 8. Hierarquização dos significados construídos pelos estudantes durante a realização do EP do microscópio de raios gama de Heisenberg.

\begin{tabular}{|c|c|c|}
\hline \multicolumn{3}{|c|}{ EP1 - Microscópio de raios gama de Heisenberg } \\
\hline Subordinados (Incerteza) & $\begin{array}{c}\text { Superordenados (Relação de } \\
\text { incerteza entre duas grandezas } \\
\text { físicas) }\end{array}$ & $\begin{array}{c}\text { Combinatórios (Exatidão, } \\
\text { precisão, incerteza) }\end{array}$ \\
\hline $\begin{array}{l}\text { A3 - Quanto menor for } \lambda \text {, } \\
\text { menor a incerteza na } \\
\text { posição do elétron. } \\
\text { A2 - Quanto menor for } \lambda \text {, } \\
\text { maior a incerteza no } \\
\text { momento do elétron. } \\
\text { A4 - É impossível reduzir } \\
\text { simultaneamente as duas } \\
\text { incertezas. } \\
\text { A1 - Ao diminuirmos o } \\
\text { valor de uma das incertezas, } \\
\text { o outro deve aumentar para } \\
\text { manter a igualdade na } \\
\text { equação. }\end{array}$ & $\begin{array}{l}\text { A3 - Quanto mais aumentamos } \\
\text { a precisão na medida da } \\
\text { posição, mais isso interfere na } \\
\text { precisão do momento. } \\
\text { A1 - Visto que o lado esquerdo } \\
\text { da igualdade é um produto } \\
\text { entre } \Delta \mathrm{x} \text { e } \Delta \mathrm{px} \text {, nesse caso, ao } \\
\text { diminuir um dos valores, o } \\
\text { outro deveria aumentar para } \\
\text { manter a igualdade. }\end{array}$ & $\begin{array}{l}\text { A3 - Diminuindo o comprimento } \\
\text { de onda do fóton, diminuímos a } \\
\text { incerteza na posição do elétron, } \\
\text { visto que a área "varrida" pelo } \\
\text { fóton seria menor. } \\
\text { A2 - Quando você mede a } \\
\text { posição do elétron, a área varrida } \\
\text { pelo raio gama sempre vai ter } \\
\text { uma largura, isso faz com que } \\
\text { não se tenha total certeza de } \\
\text { onde ele está. } \\
\text { A4 - É impossível conhecer com } \\
\text { precisão a posição e o momento } \\
\text { do elétron simultaneamente. }\end{array}$ \\
\hline
\end{tabular}

Fonte: Autores.

Como é possível observar por meio da análise dos significados dispostos no Quadro 8, os significados produzidos pelos estudantes são apresentados predominantemente em forma de proposições.

Destacamos que os significados dispostos no Quadro 8 foram sistematizados a partir da análise dos textos individuais de cada estudante. Esses textos foram produzidos durante a realização dos EPs, ou seja, os estudantes foram desafiados a relatar em um texto escrito o desenvolvimento do experimento. Nesse sentido, foram organizadas proposições que fossem 
representativas da maior parte dos elementos identificados nos materiais produzidos individualmente pelos estudantes. Salientamos, também, que os significados foram sistematizados e hierarquizados independentemente de estarem de acordo com aquilo que é aceito cientificamente - essas questões serão melhor problematizadas nas considerações finais deste texto.

Uma confusão conceitual que pôde ser evidenciada na análise dos dados está relacionada ao significado de precisão. Nas suas respostas e nos diálogos, os estudantes utilizaram vários termos, como precisão, "conhecer o valor", porém, pelo contexto de suas falas, pareceu que estavam tentando se referir à resolução de uma medida individual. Essa mesma confusão conceitual foi evidenciada no estudo desenvolvido por Montenegro e Pessoa Jr. (2002), em que, segundo os autores, os alunos utilizaram vários termos diferentes para designar que o princípio impõe uma limitação na exatidão da medição simultânea da posição e do momento do elétron. A partir dos dados de seu estudo, os pesquisadores puderam observar que os termos se situavam entre dois polos: um deles relacionado a características de medições, como "precisão", "resolução"; e o outro relacionado ao nosso "conhecimento", ou "ignorância" acerca do mundo natural. Em nosso estudo, essa mesma confusão de conceitos relacionados à precisão, resolução e incerteza, que pode ser resultado da falta de clareza conceitual, ou da dificuldade de se expressar com termos coerentes, foi evidenciada também no teste inicial. Todavia, não aventamos aqui aprofundar a discussão sobre as razões pelas quais esses problemas ocorreram, pois essa análise, além de fugir ao escopo da pesquisa, demandaria uma gama maior de dados.

A análise das produções realizadas pelos estudantes durante a atividade do EP1 possibilitou identificar conceitos como medição, espalhamento Compton, comprimento de onda e incerteza, que se tornaram mais bem diferenciados, permitindo inferir que foi possível evidenciar indícios de aprendizagem significativa. Isso remete à inferência de que foi igualmente possível promover aquilo que Ausubel, Novak e Hanesian (1983) chamam de diferenciação progressiva, ou seja, a interação promovida pela tarefa de aprendizagem leva a que novos conceitos sejam desenvolvidos, elaborados e diferenciados no que diz respeito a seus detalhes e especificidades.

\section{ii) Encontro 3: EP "Gato de Schrödinger"}

O segundo EP selecionado foi o sugerido por Erwin Schrödinger, por volta de 1935, com o intuito de ilustrar outro princípio fundamental da Mecânica Quântica, no caso, o princípio de superposição de estados. O EP em questão é o que ficou conhecido como "Gato de Schrödinger" e consiste em imaginar que um gato é aprisionado em uma caixa, totalmente isolado do meio externo. No interior da caixa existe uma substância radioativa com a probabilidade de $50 \%$ de decair e de $50 \%$ de não decair durante a realização da experiência. Um contador Geiger é acionado se o elemento decair, liberando veneno no interior da caixa e matando o gato, porém, se o elemento não decair, o veneno não é liberado e o gato sobrevive. A questão central do experimento consiste em definir se o gato está vivo ou morto, sem abrir a caixa, abrindo-a apenas posteriormente. Esse EP é classificado por Brown (1991) como destrutivo, mas não por evidenciar algo inconsistente ou incorreto na Mecânica Quântica, e sim por demonstrar como pode ser visto aparentemente como contraditório e contraintuitivo o Princípio de Superposição da Mecânica Quântica ao ser levado ao limite macroscópico. No Quadro 9 apresentamos o texto orientador entregue aos estudantes para a realização do EP. 
Quadro 9. Texto de apoio para a realização do EP2.

\section{EP2: GATO DE SCHRÖDINGER}

\section{Apresentação da atividade}

Para ilustrar um dos princípios fundamentais da Mecânica Quântica, na década de 1930, o físico austríaco Erwin Schrödinger propôs um experimento de pensamento que se tornou famoso na comunidade científica e fora dela. Trata-se do experimento de pensamento do "Gato de Schrödinger". O experimento consiste em colocar um gato aprisionado em uma caixa, totalmente isolado do meio externo. No interior da caixa é colocada uma substância radioativa, que possui a probabilidade de decair, mas também de não decair, em uma situação idealizada poderíamos afirmar que existe $50 \%$ de probabilidade de ocorrer o decaimento e $50 \%$ de não ocorrer durante a realização da experiência. Se ocorrer o decaimento, um contador Geiger acionará um dispositivo que liberará veneno dentro da caixa, matando o gato, porém, se não ocorrer o decaimento, o dispositivo não libera o veneno e o gato sobrevive.

\section{Formulação do problema}

Considerando a situação descrita, apresente a solução dos problemas propostos. Todo o andamento do experimento de pensamento deve ser relatado na folha em anexo, e esse relato deve conter o maior número possível de informações, tais como texto, desenhos, diagramas, gráficos, cálculos, etc.

$1^{\circ}$ Problema: Considerando que, com a caixa fechada, não existe qualquer interação entre um observador externo e seu interior, nesse caso, é possível este definir em qual dos estados (vivo ou morto) o gato se encontra?

$2^{\circ}$ Problema: Qual é a consideração que o observador externo poderá fazer sobre o estado do gato sem abrir a caixa?

$3^{\mathbf{0}}$ Problema: O que acontecerá se o observador abrir a caixa? Ou seja, como ficaria a definição acerca do estado do gato?

Fonte: Autores.

O EP2 foi desenvolvido considerando a sequência do conteúdo programático do componente curricular Física Moderna II. Sua aplicação ocorreu após ter sido deduzida a equação de Schrödinger e, consequentemente, após terem sido discutidos seus fundamentos e algumas de suas aplicações. Nesse sentido, o objetivo foi que os estudantes, ao se depararem com a problemática sugerida pelo EP, pudessem construir o significado referente ao Princípio de Superposição de estados quânticos.

\section{Apresentação dos significados identificados - Encontro 3}

A análise das produções escritas pelos estudantes durante a realização do EP2 possibilitou identificar a construção de significados por parte deles. A seguir destacamos trechos selecionados a partir desses registros, nos quais foram realizados alguns ajustes de linguagem para melhor compreensão. Com relação ao EP2 apresentado no Quadro 9, selecionamos os seguintes trechos, que julgamos representativos das produções dos estudantes.

Al - Antes de se observar o interior da caixa, o gato está em um estado de superposição, nesse caso, vivo e morto; $50 \%$ de probabilidade de ele estar vivo e $50 \%$ de estar morto; nesse experimento o estado já estava definido, só era desconhecido, pois não foi observado. 
A2 - Antes da medição o evento tem caráter probabilístico, depois se torna determinístico. O gato tem $50 \%$ de probabilidade de estar vivo e $50 \%$ de probabilidade de estar morto.

A3 - Impossível predizer o estado do gato (vivo ou morto); esse fator extra (inferência sobre o estado do gato) gera o que se conhece como colapso da função de onda; o colapso obriga o sistema, antes em estado de superposição, a seguir pelo caminho A ou B, ou seja, vivo ou morto. Ao abrirmos a caixa temos um fator extra que obriga o sistema a escolher um dos estados.

A4 - No experimento proposto é impossível obter dados empíricos, nesse caso é impossível concluir qual é o estado do gato; a única definição possível é de que existe $50 \%$ de probabilidade de o gato estar vivo e 50\% de estar morto; ao abrir a caixa o observador poderia facilmente definir se gato está vivo ou morto.

\section{Hierarquização dos significados construídos durante o encontro 3}

No processo de hierarquização, para o EP2, consideramos como subordinados os significados relacionados ao conceito de superposição. Ou seja, entendemos que a ideia de superposição é algo geral na Física, pois existem muitos exemplos de sistemas superpostos que não necessariamente estão vinculados ao princípio de superposição da Mecânica Quântica. Para a aprendizagem superordenada, consideramos os significados mais gerais construídos pelos estudantes e que pudessem ser relacionados às ideias específicas associadas à possibilidade de se definir o estado de um sistema físico. A aprendizagem combinatória ocorre quando o novo significado se relaciona com a estrutura cognitiva de forma mais ampla, nesse sentido, classificamos para esse tipo de aprendizagem os conhecimentos associados à relação entre medição, observação, incerteza e probabilidade.

Quadro 10. Hierarquização dos significados construídos pelos estudantes durante a realização do EP do Gato de Schrödinger.

\begin{tabular}{|c|c|c|}
\hline \multicolumn{3}{|c|}{ EP2 - Gato de Schrödinger } \\
\hline $\begin{array}{l}\text { Subordinados } \\
\text { (Superposição) }\end{array}$ & $\begin{array}{c}\text { Superordenados } \\
\text { (Possibilidade de definir um } \\
\text { estado para um sistema físico) }\end{array}$ & $\begin{array}{c}\text { Combinatórios } \\
\text { (Medição/observação, incerteza, } \\
\text { probabilidade) }\end{array}$ \\
\hline $\begin{array}{l}\text { A3 - Ao abrirmos a caixa, o } \\
\text { sistema se obriga a escolher } \\
\text { um dos estados. } \\
\text { A4 - Impossível predizer o } \\
\text { estado do gato (vivo ou } \\
\text { morto). } \\
\text { A1 - O sistema está em um } \\
\text { estado de superposição. } \\
\text { A1 - Ele está em apenas um } \\
\text { estado, que não pode ser } \\
\text { definido pois não foi } \\
\text { observado. }\end{array}$ & $\begin{array}{l}\text { A3 - O colapso obriga o } \\
\text { sistema, antes em estado de } \\
\text { superposição, a seguir pelo } \\
\text { caminho A ou B, ou seja, vivo } \\
\text { ou morto. } \\
\text { A2 - Antes da medição o evento } \\
\text { tem caráter probabilístico, } \\
\text { depois se torna determinístico. } \\
\text { A3 - Ao abrirmos a caixa, o } \\
\text { sistema se obriga a escolher um } \\
\text { dos estados. } \\
\text { A1 - Nesse experimento o } \\
\text { estado já estava definido, só era } \\
\text { desconhecido. }\end{array}$ & $\begin{array}{l}\text { A3 - Para realizar a medição } \\
\text { alteramos os fatores presentes } \\
\text { na situação. } \\
\text { A4 - É impossível fazer } \\
\text { qualquer medição sobre o } \\
\text { estado do gato e isso acaba } \\
\text { gerando incerteza sobre qual é o } \\
\text { seu estado. } \\
\text { A3 - Esse fator extra, gera o que } \\
\text { se conhece como colapso da } \\
\text { função de onda. } \\
\text { A4 - A medição elimina a } \\
\text { incerteza sobre o estado do gato. }\end{array}$ \\
\hline
\end{tabular}

Fonte: Autores. 
A resposta mais "complexa" no que diz respeito ao princípio de superposição foi a de A3, que foi enquadrada na segunda categoria (Coexistência de estados e colapso da função de onda). Em suas construções, A3 afirma que, até que se faça a medição, os dois estados (vivo e morto) coexistem em um estado de superposição. Segundo as suas considerações, ao abrirmos a caixa, o sistema se obriga a escolher um dos estados, e isso ocorre por que, em suas palavras, "ao realizarmos a medição e inferirmos no sistema mudamos os fatores presentes na situação e interferimos no resultado obtido". A3 encerra mencionando que, ao realizarmos o processo de medição, geramos o colapso da função de onda, o que obriga o sistema, antes em superposição, a escolher um dos estados.

A partir da análise dos dados, A3 pode ser tomado como exemplo no que diz respeito aos processos de diferenciação progressiva e reconciliação integrativa. No teste inicial, A3 respondeu que superposição na Física ocorre quando "Dois ou mais estados se misturam em um só", o que, desconsiderando qualquer exigência de linguagem mais técnica ou matemática, está de acordo com o significado desse fenômeno. Esse estudante também deu um exemplo de superposição de ondas e mostrou ter conhecimento prévio acerca do conceito de probabilidade. Com base na hierarquização dos dados obtidos por meio das suas produções, durante a realização do EP2, foi possível constatar que A3 construiu, a partir da situação hipotética, uma descrição bastante precisa acerca do conceito de superposição de estados quânticos, mencionando, inclusive, a ideia de colapso da função de onda, estabelecendo muitas interrelações entre seus conhecimentos prévios e as construções necessárias para resolver o problema levantado pelo experimento. Além disso, A3 estabeleceu relações importantes entre os conceitos de medição, observação, incerteza e probabilidade. Tais considerações nos dão respaldo para inferir que houve mobilização de elementos cognitivos em processos de diferenciação progressiva e reconciliação integrativa dos conhecimentos por parte desse estudante durante a realização dos EPs.

A1 também realizou construções coerentes na realização do EP2, todavia, apresentou considerações que diferem das de A3 no âmbito da interpretação do resultado do experimento. De acordo com as suas construções, o gato se encontra em um estado de superposição, todavia, isso ocorre somente pelo fato de que não temos ferramentas para conhecer o seu estado, que na verdade é bem definido, ou seja, existem variáveis que não podem ser definidas ou observadas no processo de medição.

Esses elementos, trazidos principalmente por A1 e A3, podem ser relacionados, de certa maneira, a diferentes interpretações possíveis do resultado do EP. Segundo Pessoa Jr. (2006), existem dezenas de interpretações diferentes acerca da Mecânica Quântica, porém todas elas obedecem ao mesmo formalismo. As construções dos acadêmicos podem, em certa medida, indicar uma relação com essas diferentes interpretações. Embora a análise da relação entre os dados coletados na pesquisa e as diferentes interpretações da Mecânica Quântica não faça parte do escopo deste artigo, pode ser um bom indicativo para estudos futuros envolvendo EPs.

\section{CONSIDERAÇÕES FINAIS}

Com base no presente estudo e tomando como referencial a questão central do estudo, inferimos que o uso de EPs no ensino de Física pode se configurar como uma atividade potencialmente significativa. Os procedimentos de análise aplicados sobre os dados produzidos, permitiram evidenciar indícios de aprendizagem significativa, na medida em que conhecimentos já existentes na estrutura cognitiva dos estudantes foram mobilizados pelos problemas levantados por meio dos EPs e se relacionaram, em grande parte, de forma substantiva e não arbitrária, com os novos conhecimentos. Tais considerações nos dão respaldo 
para defender que o uso de EPs no ensino de Física pode se revelar uma ferramenta que favorece a construção de significados sobre os fenômenos e princípios físicos envolvidos.

Conforme Ausubel, Novak e Hanesian (1983), os significados produzidos são organizados de modo hierárquico na estrutura cognitiva dos aprendizes. Todavia, essas relações hierárquicas não são sequências rígidas, ou seja, não significa que a aprendizagem subordinada ocorre necessariamente antes das demais. Essas relações tampouco são excludentes, isto é, a aprendizagem de determinado significado pode ser entendida, simultaneamente, como subordinada e como combinatória, por exemplo. Em nosso estudo, organizamos os significados evidenciados por meio da análise dos dados em termos de sua hierarquização - exemplificado no estudo por um dos episódios de ensino. Essa disposição facilitou a interpretação dos resultados e a identificação de indícios da ocorrência da diferenciação progressiva e da reconciliação integrativa durante a realização dos EPs.

Em determinados casos, os participantes construíram significados equivocados sobre os fenômenos físicos. Para alguns, percebemos que essa construção equivocada estava relacionada a uma falta de clareza conceitual ao lidar com as situações propostas. Conforme Pozo (1998), os conceitos são as unidades básicas do significado, de modo que, sem a compreensão conceitual, os significados produzidos têm grande chance de serem equivocados. Acrescentamos a isso a observação de que a aprendizagem significativa não é sinônimo de aprendizagem correta (Moreira, 1999; Bastos \& Mattos, 2009; Quiabao et al., 2019). Muitas vezes, alguns significados idiossincráticos podem ser coerentes para o estudante que os produziu, mas não em relação àquilo que é aceito pela comunidade científica. Em nosso estudo, em alguns casos, foram identificadas tais incoerências nas construções efetuadas pelos estudantes. Um exemplo está associado à confusão apresentada por alguns participantes quanto ao conceito de precisão, especificamente no que tange à diferença entre precisão e resolução de medida. Contudo, sempre que isso ocorreu, foi realizado um debate, estimulando a argumentação, e, com a intervenção do professor, somada à participação e colaboração entre os colegas, buscou-se um entendimento das situações alinhado aos conhecimentos aceitos e vigentes no meio científico.

A hipótese inicial, e que se confirmou no estudo, é a de que os EPs podem contribuir para a aprendizagem significativa dos conceitos e fenômenos físicos, revelando-se tarefas potencialmente significativas para o ensino de Física. Tal hipótese é reafirmada a partir da identificação do escasso uso didático dos EPs, o que nos levou a questionar sua contribuição para a aprendizagem em Física. Por lidarem com a imaginação e representação interna, os EPs não permitem ao professor ter acesso aos elementos que estão sendo mobilizados pelos estudantes durante o exercício de pensar sobre dada situação. Essa característica os diferencia dos ECs, em que os elementos postos para desenvolver a atividade estão disponíveis a todos e visíveis sobre as bancadas. No caso dos EPs, o professor precisa ficar atento àquilo que os estudantes externalizam, para que consiga captar a forma como o pensamento está se estruturando e como os conhecimentos estão sendo elaborados. Na investigação realizada, foi possível identificar que, quanto maior a bagagem de conhecimentos que o estudante tem, maiores serão as conexões estabelecidas e, consequentemente, mais rica será a construção hipotética necessária para a realização do EP, como já propõe a TAS.

A principal contribuição desta pesquisa reside em trazer elementos capazes de fomentar o engajamento de professores de Física na utilização de EPs em suas aulas, seja em nível de ensino superior ou de educação básica. Cabe-nos salientar que os professores precisam ter clareza da riqueza e da diversidade de significados que podem ser elaborados pelos estudantes durante esse tipo de atividade.

Ressaltamos, contudo, a necessidade da realização de mais estudos que busquem investigar as potencialidades do uso dos EPs no âmbito educacional. Essas investigações futuras 
podem abordar outros conteúdos específicos, diferentes níveis de escolaridade, ou se fundamentar em outros referenciais teóricos, o que traria uma gama mais ampla de conhecimentos à área que ainda não são muito explorados na Educação em Ciências. Dentre os vislumbres de estudos futuros, enfatizamos a possibilidade de se realizar uma pesquisa em sala de aula onde os estudantes realizariam os EPs com o auxílio de simulações computacionais, ou qualquer outro tipo de mídia digital. Como exemplo, citamos o trabalho desenvolvido por Reiner (1998), em que os estudantes foram desafiados a realizar um EP, envolvendo conteúdos de Óptica, com o uso de um software (Dynagrams), para a construção das situações hipotéticas por meio de simulações computacionais criadas pelos próprios participantes.

\section{REFERÊNCIAS}

Arruda, S. M., \& Laburú, C. E. (1998). Considerações sobre a função do experimento no ensino de ciências. In R. Nardi (Org.). Questões atuais no ensino de ciências. (pp. 53-60). São Paulo, SP: Escrituras Editora.

Ausubel, D. P., Novak, J. D., \& Hanesian, H. (1983). Psicología Educativa: un punto de vista cognoscitivo. 2. ed. Cidade do México, México: Editorial Trillas.

Bastos, P. W., \& Mattos, C. R. (2009). Um exemplo da dinâmica do perfil conceitual como complexificação do conhecimento cotidiano. Revista Electrónica de Enseñanza de las Ciencias, 8(3), 1054-1078.

Borges, T. (2002). Novos rumos para o laboratório escolar de Ciências. Caderno Brasileiro de Ensino de Física, 19(3), 291-313.

Brown, J. R. (1991). The Laboratory of the mind. London: Routledge.

Galilei, G. (2001). Diálogo sobre os dois máximos sistemas do mundo ptolomaico e copernicano. Trad. Pablo Ruben Mariconda. São Paulo: Editora 34.

Helm, H., \& Gilbert, J. (1985). Thought experiments and physics education - Part 1. Physics Education, 20(3), 124-131.

Hofstein, A., \& Lunetta, V. N. (2004). The laboratory in science education: Foundations for the twenty-first century. Science education, 88(1), 28-54.

Kiouranis, N. M. M. (2009). Experimentos mentais no ensino de ciências: implementação de uma sequência didática. Tese de Doutorado. Programa de Pós-Graduação em Educação para a Ciência), Universidade Estadual Paulista "Júlio de Mesquita Filho", Bauru, SP

Mach, E. (1972). On Thought Experiments. Florida, USA: University of South Florida.

Millar, R. (1987). Towards a role for experiment in the science teaching laboratory. Studies in Science Education, 14(1), 109-118.

Montenegro, R. L., \& Pessoa Jr., O. (2002). Interpretações da teoria quântica e as concepções dos alunos do Curso de Física. Investigações em Ensino de Ciências, 7(2), 107-126.

Moreira, M. A. (1999). Teorias de aprendizagem. São Paulo: EPU, 1999. 
Moreira, M. A. (2016). A Teoria da Aprendizagem Significativa: subsídios teóricos para o professor pesquisador em ensino de Ciências. Porto Alegre, RS: Brasil.

Moreira, M. A. (2002). Pesquisa em educação em ciências: métodos qualitativos. Programa Internacional de Doctorado en Enseñanza de las Ciencias. Universidad de Burgos, Espanha; Universidade Federal do Rio Grande do Sul, Brasil. Texto de Apoio ${ }^{\circ}{ }^{14}$. Publicado em Actas del PIDEC, 4, 25-55.

Moreira, M. A., \& Masini, E. A. F. S. (2001). Aprendizagem Significativa: a teoria de David Ausubel. São Paulo, SP: Centauro.

Palmero, M. L. R., Moreira, M. A., Caballero Sahelices, C. \& Greca, I. (2008). La Teoría del Aprendizaje Significativo. In M. L. R. Palmero, M. A. Moreira, \& I. Greca (Orgs.). La teoría del aprendizaje significativo em la perspectiva de la psicología cognitiva pp. 7-45. Barcelona, Espanha: Ediciones Octaedro.

Pessoa Jr, O. (2006). Conceitos de Física quântica. v. 1, São Paulo: Livraria da Física.

Pozo, J. I. (1998). A solução de problemas: aprender a resolver, resolver para aprender. Porto Alegre, RS: Artmed.

Quiabao, M. P., Silva, A. C., Almeida, N. S., Silva, R. M. A., Muniz, S. R., \& Paiva, F. F. (2019). Investigando a compreensão conceitual em física de alunos de graduação em cursos de ciências, engenharias e matemática. Revista Brasileira de Ensino de Física, 41(2), e20180258.

Reiner, M. (1998). Thought experiments and collaborative learning in physics. International Journal of Science Education, 20(9), 1043-1058.

Reiner, M., \& Gilber T, J. (2000). Epistemological resources for thought experimentation in science learning. International Journal of Science Education, 22(5), 489-506.

Velentzas, A., \& Halkia, K. (2013). The use of thought experiments in teaching physics to upper secondary-level students: two examples from the theory of relativity. International Journal of Science Education, 35(18), 3026-3049. 
Alisson Cristian Giacomelli, Doutor em Educação pela Universidade de Passo Fundo, RS, Professor do Curso de Física-L da Universidade de Passo Fundo, Passo Fundo, RS, Brasil.

Grupo de Pesquisa em Educação Científica e Tecnológica (GruPECT).

E-mail: alissongiacomelli@upf.br

Cleci Teresinha Werner da Rosa, Doutora em Educação Científica e Tecnológica pela Universidade Federal de Santa Catarina, SC, Docente do Programa de Pós-Graduação em Educação e do Programa de Pós-Graduação em Ensino de Ciências e Matemática, Universidade de Passo Fundo, Passo Fundo, RS, Brasil.

Grupo de Pesquisa em Educação Científica e Tecnológica (GruPECT).

E-mail: cwerner@upf.br

Contato

Alisson Cristian Giacomelli

Universidade de Passo Fundo

Campus I - BR 285 - Bairro São José

Passo Fundo, RS, Brasil - Cep 99052-900

Editor Responsável Geide Rosa Coelho

Centro de Ensino de Ciências e Matemática de Minas Gerais - CECIMIG Faculdade de Educação - Universidade Federal de Minas Gerais revistaepec@gmail.com 